\title{
Effects of Cooling Rate on Strength and Microstructure of Powder Metallurgy Superalloys
}

\author{
Gokhan Yıldız ${ }^{1}$, Ali Gursel ${ }^{2}$, Enes Akca ${ }^{1}$ \\ ${ }^{1}$ Department of Mechanical Engineering, Faculty of Engineering and Natural Sciences, International University of Sarajevo \\ ${ }^{2}$ Department of Mechanical Engineering, Faculty of Engineering, Duzce University
}

\begin{tabular}{l} 
Article Info \\
\hline Article history: \\
Received Jan $19^{\text {th }}, 2017$ \\
Revised Aug $19^{\text {th }}, 2017$ \\
Accepted Oct $18^{\text {th }}, 2017$ \\
\hline
\end{tabular}

Keyword:

Powder Metallurgy

Cooling Rate

Superalloys

\begin{abstract}
The excellent mechanical properties of powder metallurgy superalloys strongly depend on the microstructure, grain size, morphology, and size distribution of the $\gamma^{\prime}$ precipitates. In this study, the effects of cooling rate on strength and microstructure of powder metallurgy superalloys were investigated. Articles were reviewed about this topic and they all were evaluated. Different types of powder metallurgy superalloys such as FGH4096, U720LI, UDIMET 500, MAR-M247, K465, IN738LC, Rene88DT, CM247LC and K5 were selected for this study. These materials were tested in different parameters (temperature and time) and different cooling rates were applied. Test results showed that cooling rate has considerable effects on strength and microstructure of powder metallurgy superalloys. It was observed that the strength increased by the increment of cooling rate. Also, almost homogeneous microstructure was obtained at high cooling rate.
\end{abstract}

\section{Corresponding Author:}

GokhanYıldız,

Departement of Mechanical Engineering,

International University of Sarajevo,

Hrasnickacesta 15, 71210, Sarajevo, Bosnia and Herzegovina.

Email: gokhan.yildiz1987@hotmail.com

\section{Introduction}

The excellent high temperature performance of a nickel-based powder metallurgy alloy depends most often on strengthening $\gamma^{\prime}$ precipitates. To increase the strength and flexibility of the alloy by heat treatment it is necessary to control the amount, size, morphology and distribution of the $\gamma^{\prime}$ phase [1]. In general, the volume percentage of the $\gamma^{\prime}$ phase is about $35 \%$ to $60 \%$ in the high-alloy superalloy. The ratio $\gamma c^{\prime}$ of the cooling $\gamma^{\prime}$ precipitates formed during the cooling process exceeds $60 \%$, and therefore examination of $\gamma_{c}{ }^{\prime}$ precipitation behaviors at various cooling conditions is one of the important baseline investigations to increase the temperature ability. [2]. The grain boundaries are weak bonds in the superalloys and easily become rupture at high operating temperatures due to defects in the microstructure. Some carbides and $\gamma^{\prime}$ particles as boundary precipitants have significant effects on the high temperature creep resistance and plasticity of nickel-based superalloys. For this reason, examining the morphology and component of the micro-phase near the grain boundaries is a very important issue to strengthen the grain boundaries [2].

\section{Discussion}

Tian and et al. examined the effect of cooling rate on cooling $\gamma^{\prime}$ precipitation behavior in nickel-based powder metallurgy superalloy (FGH4096). Chemical composition of the alloy is given in Table 1. The samples were dissolved at $1150{ }^{\circ} \mathrm{C}$ for 5 minutes and then cooled to room temperature at different controlled cooling rates. 
Experimental conditions are shown in Table 2. The cooling rate plays a crucial role in controlling the amount, size, morphology and distribution of cooling $\gamma^{\prime}$ precipitates. The mean sizes of the secondary and tertiary $\gamma^{\prime}$ precipitates were inversely correlated with the cooling rate. The shape of the secondary $\gamma^{\prime}$ precipitates within grain changes from butterfly like to spherical with cooling rate. However, regardless of the cooling rate, all the tertiary $\gamma^{\prime}$ precipitates formed are spherical. The cooling rate has a significant effect on the precipitation behavior of the $\gamma^{\prime}$ phase at the grain boundaries and the apparent extent of the grain boundaries; the higher the cooling rate, the narrower the visibility of the grain boundaries [2].

Mao et al. investigated cooling precipitation and strengthening in powder metallurgy superalloy. The excellent mechanical properties of powder metallurgy superalloys depend on the microstructure such as grain size, morphology and size distribution. The microstructure is determined in turn by heat treatment quenching and then aging. Experimental conditions are shown in Table 2. To investigate the effect of quenching, two types of quenching methods (continuous cooling and interrupted cooling) were used to produce different cooled microstructures in the UDIMET 720Li (U720LI) alloy. Chemical composition of the alloy is given in Table 1. In continuous cooling tests, the tensile strength increased linearly with the cooling rate. Interrupted cooling tests have shown that $\gamma^{\prime}$ growth is a linear function of decreasing temperature for a given cooling rate. A nonmonotonic decay of the tensile strength against the interrupt temperature has been discovered [1]. Tian et al. applied two cooling schemes (continuous cooling and interrupted cooling tests) to investigate the cooling $\gamma^{\prime}$ precipitation behavior in the powder metallurgy superalloy FGH4096. Chemical composition of the alloy is given in Table 1. The maximum tensile strength of the samples was tested under various cooling conditions. Experimental conditions are shown in Table 2 . The average sizes of the secondary and tertiary $\gamma$-precipitates were obtained between the strength and the cooling rate. The results show that there is an opposite correlated between the average sizes. Interrupted cooling tests show that the mean size of secondary $\gamma^{\prime}$ precipitates increases as a linear function of the cutting temperature for a constant cooling rate of $24^{\circ} \mathrm{C} / \mathrm{min}$. The ultimate tensile strength of the alloy increases with increasing cooling rate, but it first decreases and increases with decreasing temperature caused by the third $\gamma^{\prime}$ precipitate [3].

Table 1: Chemical composition of alloys (wt \%)

\begin{tabular}{|c|c|c|c|c|c|c|c|c|c|}
\hline & $\begin{array}{c}\text { FGH409 } \\
6 \\
\end{array}$ & $\begin{array}{c}\text { U720L } \\
\text { I }\end{array}$ & $\begin{array}{c}\text { UDIME } \\
\text { T 500 }\end{array}$ & $\begin{array}{l}\text { MAR- } \\
\text { M247 }\end{array}$ & K465 & $\begin{array}{c}\text { IN738L } \\
\text { C } \\
\end{array}$ & $\begin{array}{c}\text { Rene88D } \\
\text { T } \\
\end{array}$ & $\begin{array}{c}\text { CM247L } \\
\text { C }\end{array}$ & K5 \\
\hline $\mathrm{Ni}$ & Balance & Balance & Balance & $\begin{array}{c}\text { Balanc } \\
\text { e }\end{array}$ & $\begin{array}{c}\text { Balanc } \\
\mathrm{e}\end{array}$ & Balance & 55.63 & Balance & $\begin{array}{c}\text { Balanc } \\
\mathrm{e}\end{array}$ \\
\hline $\mathrm{Cr}$ & 16.04 & 16.35 & 17.9 & 4.43 & 8.30 & 16.49 & 18.02 & 8.09 & 10.3 \\
\hline Co & 12.70 & 14.75 & 17.2 & 9.08 & 9.45 & 8.72 & 13.00 & 9.35 & 10.2 \\
\hline W & 3.98 & 1.3 & - & 7.62 & 9.85 & 3.36 & 1.21 & 9.41 & 5.1 \\
\hline $\begin{array}{c}\mathbf{M} \\
\mathbf{0}\end{array}$ & 3.84 & 3.02 & 4.00 & 2.02 & 1.78 & 1.90 & 2.48 & 0.52 & 3.96 \\
\hline Nb & 0.72 & - & - & 1.00 & 0.90 & 0.88 & 0.46 & - & - \\
\hline Al & 2.18 & 2.46 & - & 5.72 & 5.56 & 3.26 & 4.45 & 5.51 & 5.54 \\
\hline $\mathbf{T i}$ & 3.71 & 4.99 & 3.00 & - & 2.38 & 3.23 & 4.74 & 0.82 & 2.62 \\
\hline C & 0.028 & 0.025 & 0.11 & 0.012 & 0.14 & 0.06 & - & 0.075 & 0.137 \\
\hline $\mathbf{Z r}$ & 0.04 & 0.035 & - & - & - & 0.04 & - & - & - \\
\hline B & 0.0095 & - & - & - & - & 0.08 & - & - & - \\
\hline $\mathbf{N}$ & 0.0022 & - & - & - & - & - & - & - & - \\
\hline $\mathbf{S}$ & - & 0.005 & - & - & - & - & - & - & - \\
\hline $\mathbf{F e}$ & - & 0.06 & 2.1 & - & - & - & - & - & - \\
\hline $\operatorname{Re}$ & - & - & - & 2.02 & - & - & - & - & - \\
\hline Та & - & - & - & 6.74 & - & 1.63 & - & 3.24 & - \\
\hline Hf & - & - & - & 0.10 & - & - & - & 1.53 & - \\
\hline
\end{tabular}


Table 2: Experimental conditions of superalloys

\begin{tabular}{cccccccccc}
\hline Alloys & $\begin{array}{c}\text { Temperature } \\
\left({ }^{\mathbf{O}} \mathbf{C}\right)\end{array}$ & $\begin{array}{c}\text { Time } \\
(\mathbf{m i n})\end{array}$ & \multicolumn{5}{c}{ Cooling Rates $\left({ }^{\circ} \mathbf{C} / \mathbf{m i n}\right)$} \\
\hline FGH4096 & 1150 & 5 & 24 & 84 & 258 & 648 & & \\
U720LI & 1175 & 5 & 11 & 27 & 55 & 110 & 167 & 800 \\
UDIMET500 & 1080 & 240 & 3.85 & 35.4 & 49.8 & 90.35 & 129.5 & 186 \\
IN738LC & 1120 & 120 & 36 & 48 & 66 & - & - & - \\
Rene88DT & 1124 & 240 & 24 & 280 & 300 & & - & - \\
IN738LC & 1120 & 120 & 11 & 72 & 98 & 247 & 368 & - \\
CM247LC & 1230 & 120 & 81 & 125 & 168 & - & - & - \\
\hline
\end{tabular}

Sajjadi et al. investigated the effect of cooling rate on microstructure and mechanical properties. For this purpose, after making a partial solution for 4 hours at $1080^{\circ} \mathrm{C}$ on the samples of UDIMET 500. Experimental conditions are shown in Table 2. Chemical composition of the alloy is given in Table 1. The microstructures of the samples were examined using optical and electron microscopy. As a result, it was determined that the volume of $\gamma^{\prime}$ precipitates decreased with increasing cooling rate. Thus, as the cooling rate increases, homogeneity is observed in the microstructure. It is observed that the increased cooling rate increases the strength but decreases the ductility [4]. Zhang et al. investigated the development of solidification cooling rate microstructures in Ni-based superalloy using conventional casting, injection casting and melt bending methods. MAR-M247 nickel-based superalloy was selected as material. Chemical composition of the alloy is given in Table 1. The sample was dissolved at a temperature of $1273 \mathrm{~K}$ for $5 \mathrm{~min}$. Experimental conditions are shown in Table 3. As a result, irregular structures decreased as the cooling rate increased. It has been found that the interspaces of $\gamma^{\prime}$ precipitates in the cell structure reduced [5].

Table 3: Experimental Conditions of superalloys

\begin{tabular}{ccccccccc}
\hline Alloys & $\begin{array}{c}\text { Temperature } \\
(\mathbf{K})\end{array}$ & $\begin{array}{c}\text { Time } \\
(\mathbf{m i n})\end{array}$ & \multicolumn{5}{c}{ Cooling Rates (K/min) } \\
\hline MAR-M247 & 1273 & 5 & 0.72 & 2.1 & 9 & 39 & 75 & 870 \\
K465 & 1483 & 240 & 12 & 120 & 612 & - & - & - \\
MAR-M247 & 1633 & 5 & 15 & 60 & 300 & 600 & - & - \\
\hline
\end{tabular}

Pei et al. investigated the effect of cooling rate on the microstructure and mechanical properties of K465 superalloy. The chemical composition of K465 is given in Table 1. For this purpose, samples were dissolved at $1483 \mathrm{~K}$ for 4 hours. Experimental conditions are shown in Table 3. As a result, as the cooling rate increased, the size of the $\gamma^{\prime}$ precipitates decreased and the mechanical properties of the samples increased. It has also been found that the coarse $\gamma^{\prime}$ particles are greatly influenced by the cooling rate of the shape and volume fraction [6].

Kavoosi and colleagues investigated the effect of cooling rate on the microstructure and mechanical properties of the IN738LC superalloy. Chemical composition of the alloy is given in Table 1. For this purpose, it was dissolved for 2 hours at $1120^{\circ} \mathrm{C}$. Experimental conditions are shown in Table 2. As a result, as the cooling rate increased, the size of the $\gamma^{\prime}$ precipitates decreased and the mechanical properties of the samples increased. It has also been found that the shape and volume fraction of the unified $\gamma^{\prime}$ particles are greatly reduced by the effect of the cooling rate [7].

Singh et al. investigated the effect of cooling rate on the development of multiple generation $\gamma^{\prime}$ precipitates of Rene88DT superalloy. The chemical composition of Rene88DT is given in Table 1. For this purpose, it was dissolved for 4 hours at $1124{ }^{\circ} \mathrm{C}$. Experimental conditions are shown in Table 2. Continuous cooling at a very high rate after dissolving in the single gamma phase results in a high degree of nucleation and a monomodal size distribution with non-equilibrium compositions. A relatively slow cooling rate $\left(24^{\circ} \mathrm{C} / \mathrm{min}\right)$ Resulting in a multimodal size distribution; the larger first generation primary precipitates exhibit near-equilibrium composition, while the smaller-scale secondary $\gamma^{\prime}$ precipitates exhibit non-equilibrium composition [8].

Milenkovic et al. examined the effect of cooling rate on the microstructure of MAR-M247 superalloy. The chemical composition of MAR-M247 is given in Table 1. The samples were dissolved at about $1633 \mathrm{~K}$ for 5 
min. Experimental conditions are shown in Table 3. MAR-M247 showed cellular $(15 \mathrm{~K} / \mathrm{min})$ and dendritic $(60,300$ and $600 \mathrm{~K} / \mathrm{min})$ microstructures. It has been determined that the microstructures also change with the cooling rate. $\gamma / \gamma^{\prime}$ matrix with carbides and $\gamma / \gamma^{\prime}$ eutectic at $15 \mathrm{~K} / \mathrm{s}, \gamma / \gamma^{\prime}$ matrix with carbides at $60 \mathrm{~K} / \mathrm{min}$, and $\gamma / \gamma^{\prime}$ matrix with carbides and $\gamma / \mathrm{MC}$ eutectic at 300 and $600 \mathrm{~K} / \mathrm{min}$. Furthermore, it has been observed that the range of secondary dendritic arms decreases and the hardness increases as the cooling rate increases [9].

Behrouzghaemi and Mitchell examined the effect of cooling rate on the microstructure of IN738LC superalloy. The chemical composition of IN738LC is given in Table 1. The samples were dissolved at about $1120^{\circ} \mathrm{C}$ for $2 \mathrm{~h}$. Experimental conditions are shown in Table 2. As the cooling rate decreases, the $\gamma^{\prime}$ solid state shows morphological instability and the $\gamma^{\prime}$ size shrinks as the cooling rate decreases. The shape changes observed in this study revealed the effect of the cooling rate on the disturbances between $\gamma$ and $\gamma^{\prime}[10]$.

Mehta et al. examined the effect of cooling rate on the microstructure of CM247LC superalloy. The chemical composition of CM247LC is given in Table 1. The samples were dissolved at about $1230{ }^{\circ} \mathrm{C}$ for $2 \mathrm{~h}$. Experimental conditions are shown in Table 2. As a result, as the cooling rate increased, the size of the $\gamma^{\prime}$ precipitates decreased and the mechanical properties of the samples increased [11].

\section{Conclusion}

The cooling rate plays a very important role in controlling the amount, size, morphology and distribution of cooling $\gamma^{\prime}$ precipitates. The average sizes of the secondary or tertiary $\gamma^{\prime}$ precipitates are inversely correlated with the cooling rate. The shape of the secondary $\gamma^{\prime}$ precipitates in the grain varies from butterfly like to spherical with the cooling rate. However, all the tertiary $\gamma$ 'precipitates formed, irrespective of the cooling rate, are spherical.

Cooling rate has an important effect on the precipitation behaviors of $\gamma^{\prime}$ phase at grain boundaries and the apparent width of grain boundaries; the higher the cooling rate, the narrower is the apparent width of grain boundaries. As the cooling rate increased, the size of the $\gamma^{\prime}$ precipitates decreased and the mechanical properties of the samples increased. It is observed that the increased cooling rate increases the strength.

\section{References}

[1] J. Mao, K.-M. Chang, W. Yang, K. Ray, S. P. Vaze and D. U. Furrer, "Cooling Precipitation and Strengthening Study in Powder Metallurgy Superalloy U720LI," Metallurgical and Materials Transactions, vol. 32, no. 10, pp. 2441-2452, 2001.

[2] G. Tian, C. Jia, Y. Wen and B. Hu, "Effect of solution cooling rate on the $\gamma^{\prime}$ precipitation behaviors of a Ni-base P/M superalloy," Journal of University of Science and Technology Beijing, vol. 15, no. 6, pp. 729-734, 2008.

[3] G. Tian, C. Jia, Y. Wen, G. Liu and B. Hu, "Cooling $\gamma^{\prime}$ precipitation behavior and strengthening in powder metallurgy superalloy FGH4096," Rare Metals, vol. 27, no. 4, pp. 410-417, 2008.

[4] S. Sajjadi, H. R. Elahifar and H. Farhangi, "Effects of cooling rate on the microstructure and mechanical properties of the Ni-base superalloy UDIMET 500," Journal of Alloys and Compounds, vol. 455, p. 215-220, 2008.

[5] Y. Zhang, Y. Huang, L. Yang and J. Li, "Evolution of microstructures at a wide range of solidification cooling rate in a Ni-based superalloy," Journal of Alloys and Compounds, vol. 570, p. 70-75, 2013.

[6] Z.-y. Pei, W. Han, G. Zhao, X.-f. Chen, J.-t. Li and Y.-w. Tian, "Effect of Cooling Rate on Microstructure and Mechanical Properties of K465 Superalloy," Jounal of Iron and Steel Research, vol. 16, no. 6, pp. 70-74, 2009.

[7] V. Kavoosi, S. M. Abbasi, S. G. Mirsaed and M. Mostafaei, "Influence of cooling rate on the solidification behavior and microstructure of IN738LC superalloy," Journal of Alloys and Compounds, vol. 680, p. 291-300, 2016.

[8] A. Singh, S. Nag, J. Hwang, G. Viswanathan, J. Tiley, R. Srinivasan, H. Fraser and R. Banerjee, "Influence of cooling rate on the development of multiple generations of $\gamma^{\prime}$ precipitates in a commercial nickel base superalloy," Materials Characterization, vol. 62, pp. 878-886, 2011.

[9] S. Milenkovic, I. Sabirov and J. LLorca, "Effect of the cooling rate on microstructure and hardness of MAR-M247 Ni-based superalloy," Materials Letters, vol. 73, pp. 216-219, 2012.

[10] S. Behrouzghaemi and R. J. Mitchell, Materials Science and Engineering A, vol. 498, pp. 266-271, 
2008.

[11] K. K. Mehta, R. Mitra and S. Chawla, "Effect of post-solutionizing cooling rate on microstructure and low cycle fatigue behavior of a cast nickel based superalloy," Materials Science \& Engineering A, vol. 611, pp. 280-289, 2014.

[12] E. Akca and A. Gursel, "A Review on Superalloys and IN718 Nickel-Based INCONEL Superalloy," Periodicals of Engineering and Natural Sciences, vol. 3, pp. 15-27, 2015. 